УДК 378.147:004.738.5:61

\title{
АНАЛИЗ ДИСТАНЦИОННОЙ И ОЧНОЙ ФОРМЫ ОБУЧЕНИЯ В РАЗРЕЗЕ МЕДИНСКОГО ВУЗА
}

\author{
Бабаджанян Акоп Манасович \\ Кашинцев Вадим Алексеевич \\ Гросс Дарья Юрьевна
}

Красноярский государственный медицинский университет имени профессора В.Ф. Войно-Ясенецкого

Аннотация: В наши дни, в условиях пандемии, необходимо правильно организовывать работу со студентами, обучающихся в медицинских вузах, ведь грамотная подготовка студентов-медиков влияет на дальнейшее становление и формирование будущих специалистов. В условиях пандемии практически все вузы перешли на дистанционный формат обучения, необходимо было быстро подстроиться под изменяющиеся условия и выбрать грамотную стратегию образования для будущих врачей. Мы живем в эпоху бурного развития технологий перевести студентов на дистанционное обучение не составило больших трудностей, но главной проблемой стало то, что дистанционный формат имеет ряд особенностей, с которыми студенты и преподаватели столкнулись в ходе работы. В работе рассматривается влияние дистанционного формата преподавания на различные аспекты обучения у студентов. Результаты исследования могут быть использованы при переходе на дистанционное обучение. В статье рассмотрены истоки зарождения и аспекты дальнейшего развития дистанционной формы образования.

Ключевые слова: коронавирусная инфекция, дистанционное обучение, онлайн обучение, медицинское образование, современные технологии.

\section{ANALYSIS OF DISTANCE AND ESSENTIAL FORM OF LEARNING IN THE CONTEXT OF THE MEDINA UNIVERSITY}

\author{
Babadzhanyan Akop Manasovich \\ Kashintsev Vadim Alekseevich \\ Gross Darya Yuryevna
}


Abstract: In these days of the pandemic, it is necessary to properly organize the work with students studying at medical universities, because the competent training of medical students affects the further formation and formation of future specialists. During the pandemic almost all universities switched to a distance learning format, it was necessary to quickly adjust to the changing conditions and choose a competent educational strategy for future doctors. We live in the era of rapid development of technology to transfer students to distance learning was not very difficult, but the main problem was the fact that the distance format has a number of features that students and teachers encountered in the course of work. The paper examines the impact of the distance format of teaching on various aspects of learning in students. The results of the study can be used in the transition to distance learning. The article examines the origins of the origin and aspects of the further development of the distance form of education.

Keywords: COVID-19, Distance Learning, Online Learning, Medical Education, Modern technologies

Введение. Дистанционное образование довольно активно внедряется в нашу жизнь, оно стало доступно для людей с 30 мая 1997 года, выход приказа № 1050 Минобразования России, позволил проводить оценку дистанционного обучения в сфере образования (впоследствии приказ был продлён) [1].

Огромное влияние на развитие дистанционного обучения оказала эпидемиологическая ситуация и приказ Министерства просвещения Российской Федерации от 17.03.2020 № 103 [2]. Внедрение онлайн обучения помогло получать знания студентам в период пандемии. Но за время его существования возникло множество противоречий, в частности с точки зрения доступности и качества организации учебного процесса в ВУЗах.

\section{Дистанционное образование в сфере медицины}

Дистанционное образование было введено и в медицинских ВУЗах, однако данная форма обучения требует большой проработанности для ее внедрения в учебный процесс в связи со спецификой врачевания. Проработке учебного процесса при онлайн обучении уделяется огромное внимание, особенно следующим аспектам: организации видео-лекций, адаптации практических занятий и повышению качества их наглядности и доходчивости.

Адаптация учебного процесса под онлайн формат, нелегкий процесс. Сложность в подаче и получении информации, адаптации практических 
навыков, проверочные и контрольные работы - всё это сильно изменило традиционное представление об образовании.

Многие вузы по сей день придерживаются дистанционного обучения, а преподаватели возраст которых более 65 лет (Постановление Правительства РФ от 18 июня 2020 г. № 876) [3], продолжают преподавать дома, поэтому данный вопрос не перестает быть актуальным до сих пор.

Цель исследования. Проанализировать отношение обучающихся к дистанционным формам обучения.

Maтериалы и методы. Для анализа и сравнения дистанционной и очной формы обучения в медицинских вузах мы провели опрос 144 студентов I и II курса, изучающих общую хирургию и офтальмологию. Для сравнения были предложены 6 категорий.

Результаты опроса представлены в таблице 1.

Таблица 1

\section{Сравнение форматов очного и онлайн-обучения}

\begin{tabular}{|c|c|c|}
\hline $\begin{array}{c}\text { Категории } \\
\text { оценивания }\end{array}$ & Очное обучение & Дистанционный формат \\
\hline $\begin{array}{l}\text { Усвоение } \\
\text { информации }\end{array}$ & $\begin{array}{l}\text { Информация усваивается проще. } \\
\text { Это связано с тем, что при } \\
\text { живом общении преподаватель } \\
\text { может отследить недочеты и } \\
\text { проблемы студентов, с которыми } \\
\text { впоследствии он помогает } \\
\text { разобраться. } \\
\text { Немаловажным фактором } \\
\text { является сконцентрированность } \\
\text { внимания, которая вживую } \\
\text { достигается более успешно. }\end{array}$ & $\begin{array}{l}\text { Информация усваивается хуже, в } \\
\text { связи с тем, что преподавателю } \\
\text { намного труднее привлечь внимание } \\
\text { студента. Еще одним немаловажным } \\
\text { аспектом является наличие } \\
\text { множества отвлекающих факторов, } \\
\text { которые негативно влияют на } \\
\text { усвоение информации. }\end{array}$ \\
\hline $\begin{array}{l}\text { Практические } \\
\text { занятия }\end{array}$ & $\begin{array}{l}\text { Наличие практических } \\
\text { материалов позволяет закрепить } \\
\text { теоретическую информацию с } \\
\text { помощью отработки теории. }\end{array}$ & $\begin{array}{l}\text { В связи с тем, что при обучение } \\
\text { дистанционно трудно обеспечить } \\
\text { студента нужным материалом для } \\
\text { практики, качество занятий сильно } \\
\text { уступает очному. }\end{array}$ \\
\hline $\begin{array}{l}\text { Тайм- } \\
\text { менеджмент }\end{array}$ & $\begin{array}{l}\text { Время распределяется более } \\
\text { правильно, но много времени } \\
\text { уходит на перемещение между } \\
\text { учебными корпусами }\end{array}$ & $\begin{array}{l}\text { В связи с отсутствием траты времени } \\
\text { на дорогу, количество времени } \\
\text { возрастает. Но стоит отметить, что } \\
\text { многим студентам тяжело само- } \\
\text { стоятельно составить свой график, } \\
\text { поэтому у них возникают проблемы с } \\
\text { распределением времени. }\end{array}$ \\
\hline
\end{tabular}




\begin{tabular}{|l|l|l|}
\hline \multicolumn{1}{|c|}{$\begin{array}{l}\text { Категории } \\
\text { оценивания }\end{array}$} & \multicolumn{1}{|c|}{ Очное обучение } & \multicolumn{1}{|c|}{ Дистанционный формат } \\
\hline Комфорт & $\begin{array}{l}\text { Максимально комфортно в } \\
\text { стенах вуза, благодаря } \\
\text { коммуникации с другими } \\
\text { студентами и преподавателями }\end{array}$ & $\begin{array}{l}\text { Комфортно в связи с тем, что } \\
\text { студенту не обязательно находится в } \\
\text { конкретном месте. В домашних } \\
\text { условиях более удобно, имеетя своя } \\
\text { атмосфера и не нужно никуда ехать. } \\
\text { Также отмечалось, что в связи с } \\
\text { дистанционым форматом многие } \\
\text { начали испытывать дискомфорт из-за } \\
\text { долгого пребывания за компьютером: } \\
\text { сухость в глазах, боль в спине и } \\
\text { головные боли. }\end{array}$ \\
\hline $\begin{array}{l}\text { Зачеты и } \\
\text { экзамены }\end{array}$ & $\begin{array}{l}\text { Сдавать экзамен сложнее в связи } \\
\text { волнением, но знания } \\
\text { проверяются более качественно. }\end{array}$ & $\begin{array}{l}\text { Сдать экзамен проще из-за } \\
\text { отсутствия волнения, но появляется } \\
\text { возможность списывания, вероятны } \\
\text { технические проблемы. }\end{array}$ \\
\hline $\begin{array}{l}\text { Взаимодействия } \\
\text { преподавателя и } \\
\text { студентов }\end{array}$ & $\begin{array}{l}\text { Взаимодействие преподавателя } \\
\text { напрямую со студентом является } \\
\text { более комфортным, ответы на } \\
\text { вопросы поступают более } \\
\text { оперативно. }\end{array}$ & $\begin{array}{l}\text { Общение с преподавателем очень } \\
\text { ограниченное или вовсе отсутствует. }\end{array}$ \\
\hline
\end{tabular}

Анализируя данные, полученные в ходе опроса студентов, мы сформировали диаграммы и выводы по каждому из показателей.

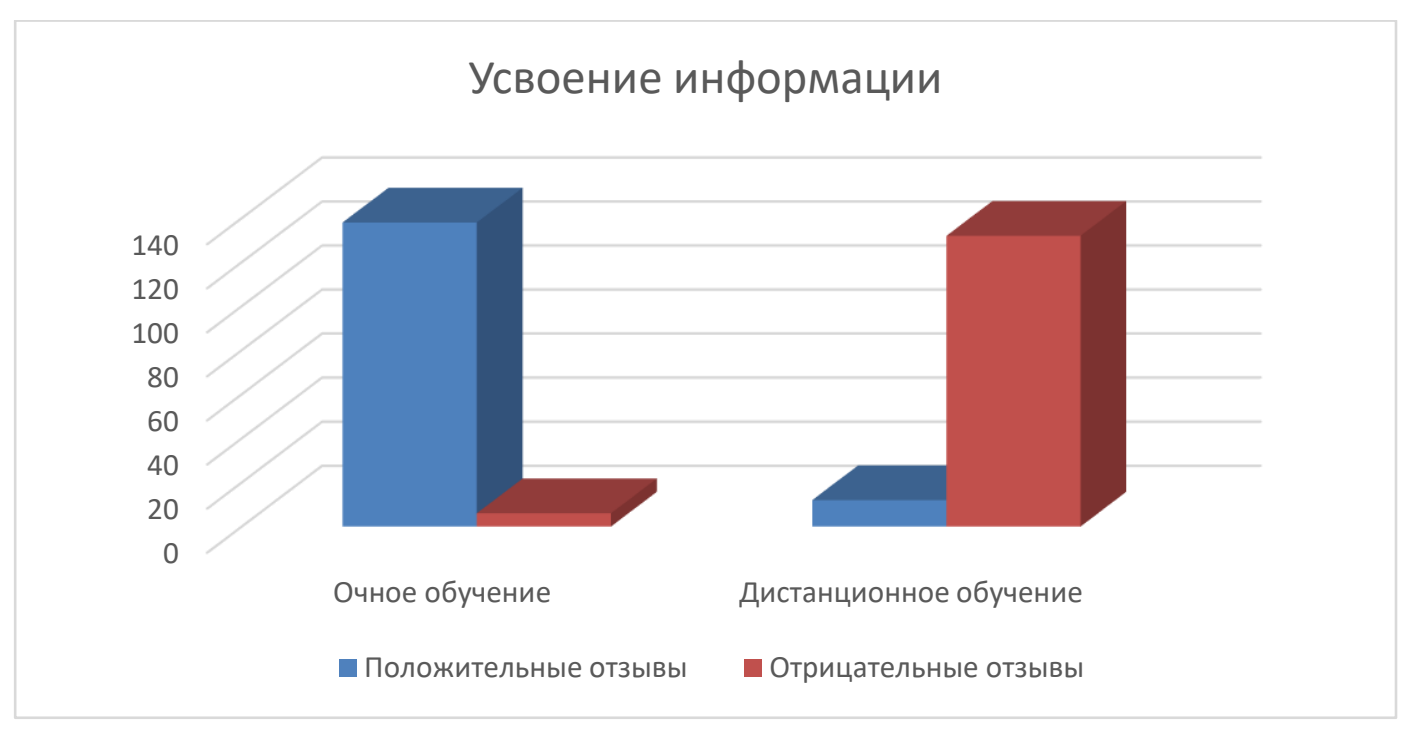

\section{Диаграмма 1. Сравнение усвоения информации при очном и дистанционном формате обучения}

Для улучшения доступности информации на дистанционном обучении прикладывается болышое количество усилий, все же данная диаграмма отражает 
то, что студентам тяжелее усваивать информацию в условиях дистанционного обучения, чем в традиционном очном формате. Лишь 8,3\% студентов не испытывают проблем с усвоением информации. Сравнивая усвоение информации в других вузах, а именно в Дубайской школой бизнеса, у них около 23,3\% студентов могут комфортно получать образование в дистанционном формате [4].

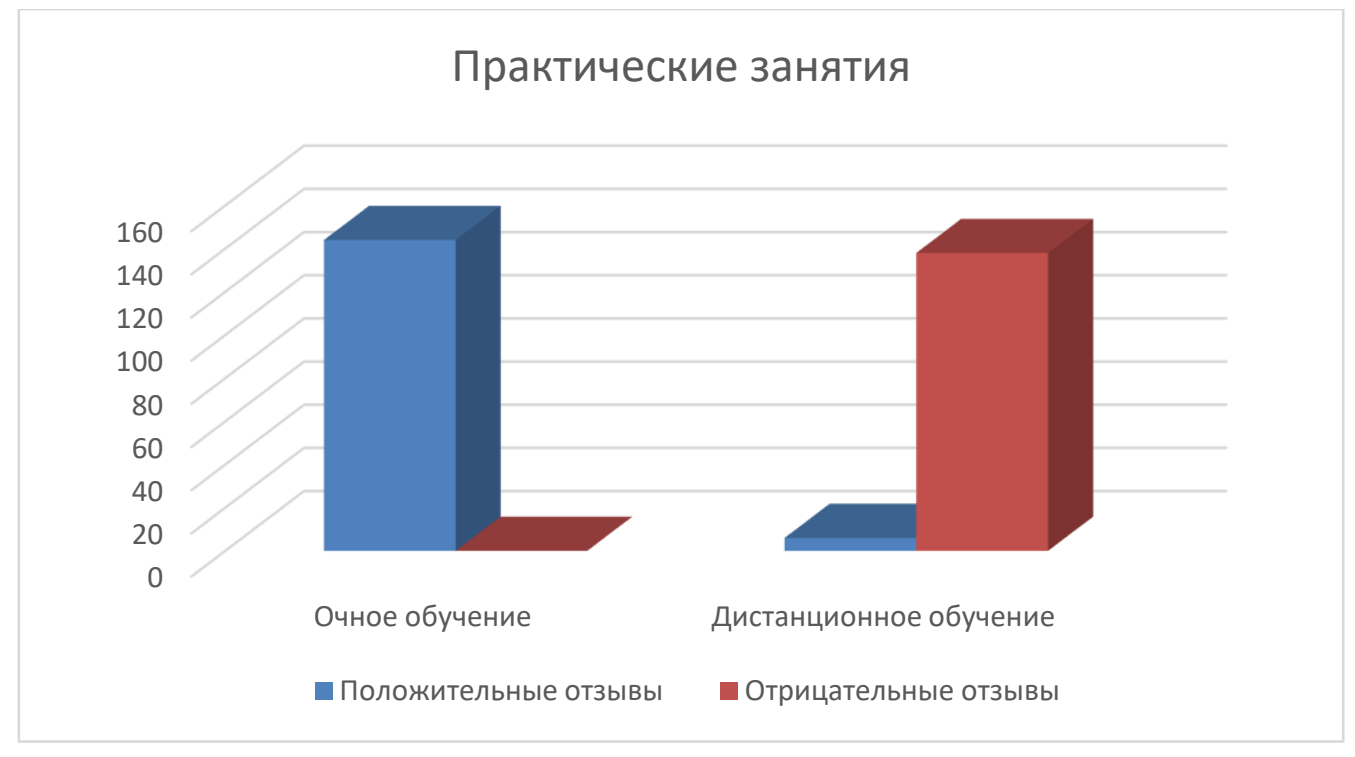

\section{Диаграмма 2. Сравнение практических занятий при очном и дистанционном формате обучения}

Как мы видим исходя из данной диаграммы получение практических навыков на очном обучении пока что никаким образом незаменимо дистанционным форматом.

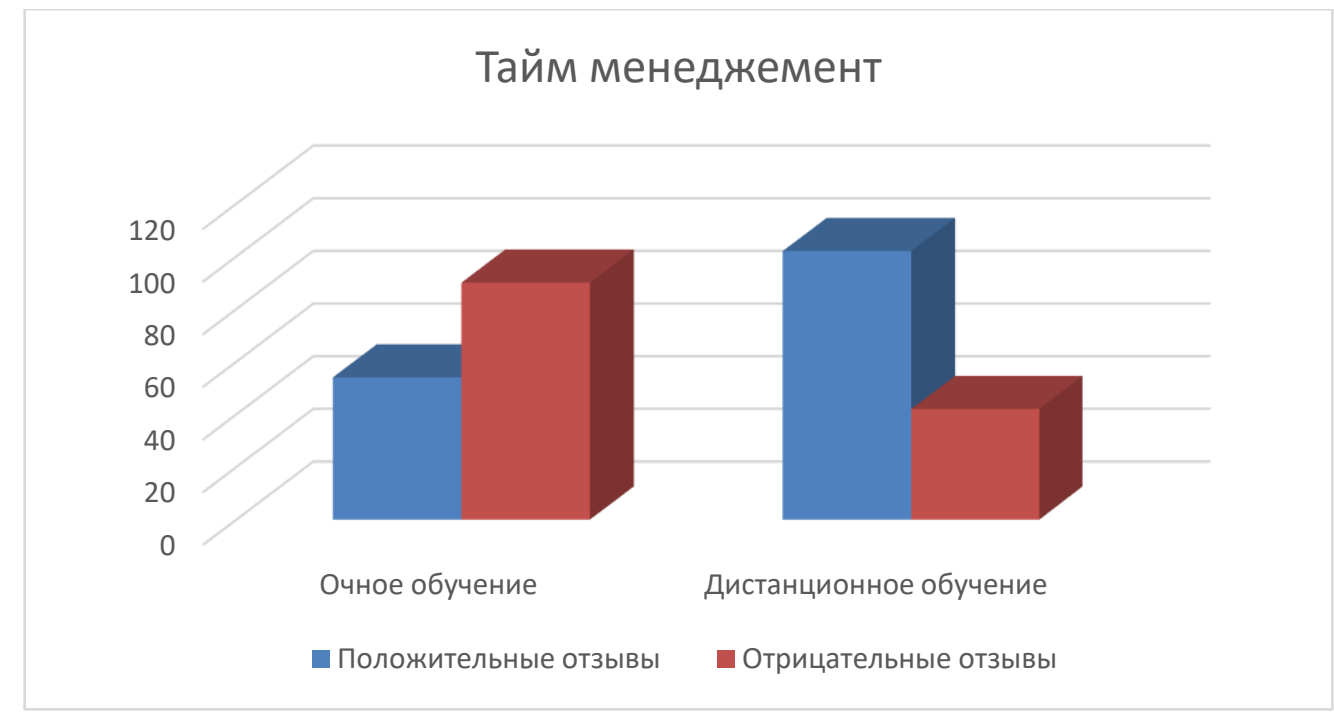

Диаграмма 3. Сравнение тайм менеджмента при очном и дистанционном формате обучения 
C распределением времени студенты справляются, как при очном, так и при дистанционном формате обучения, но большинству проще распределять время на дистанционном обучении. Около 70,8\% студентов легко распределяют время на дистанционном обучении. [4].

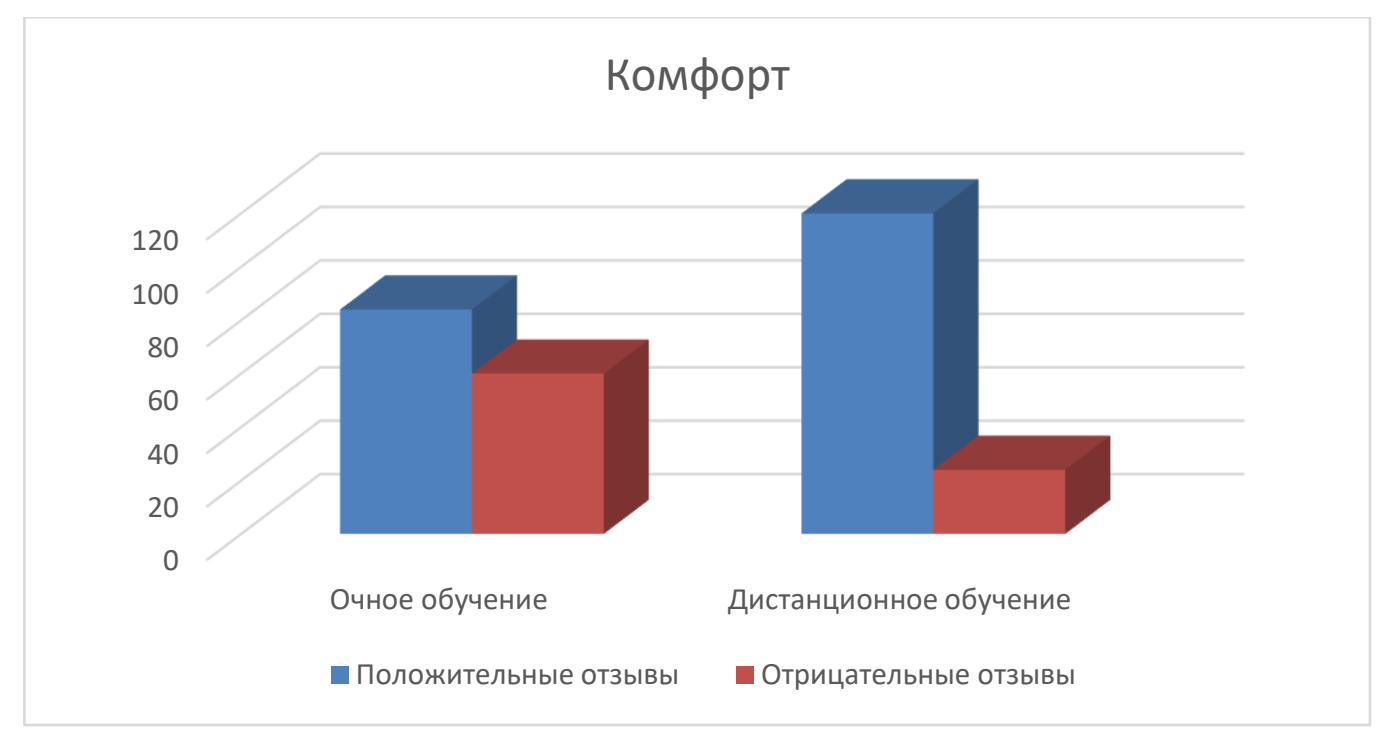

\section{Диаграмма 4. Сравнение комфорта при очном и дистанционном формате обучения}

Что касается комфорта, большинство студентов отметило, что на дистанционном формате обучения находится более комфортно, но также немалое количество студентов предпочитает и очный формат обучения.

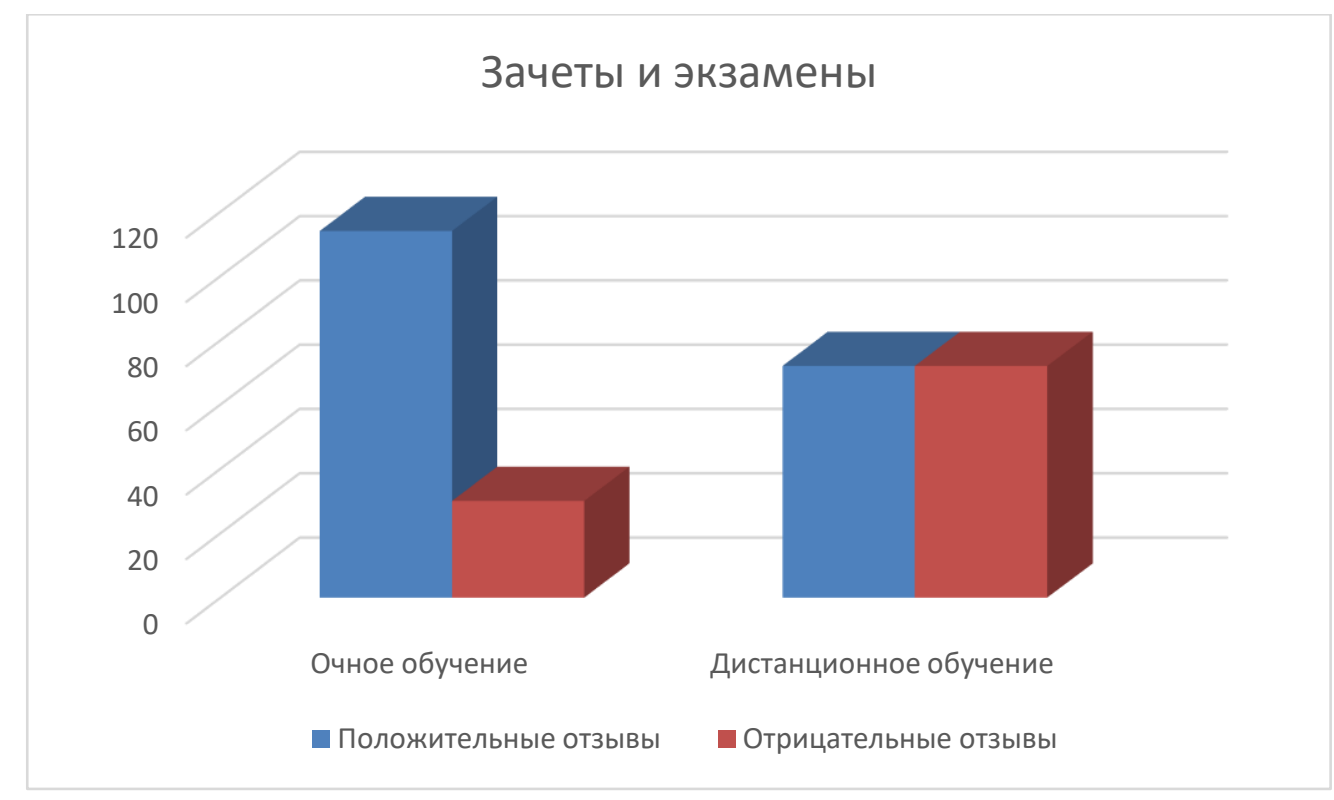

Диаграмма 5. Сравнение сдачи зачетов при очном и дистанционном формате обучения 
По результатам диаграммы 5 видно, что для студентов более предпочтительна очная сдача зачетов и экзаменов, вероятнее всего, это может быть связано с отсутствием таких проблем, как технические неполадки при сдаче в дистанционном формате.

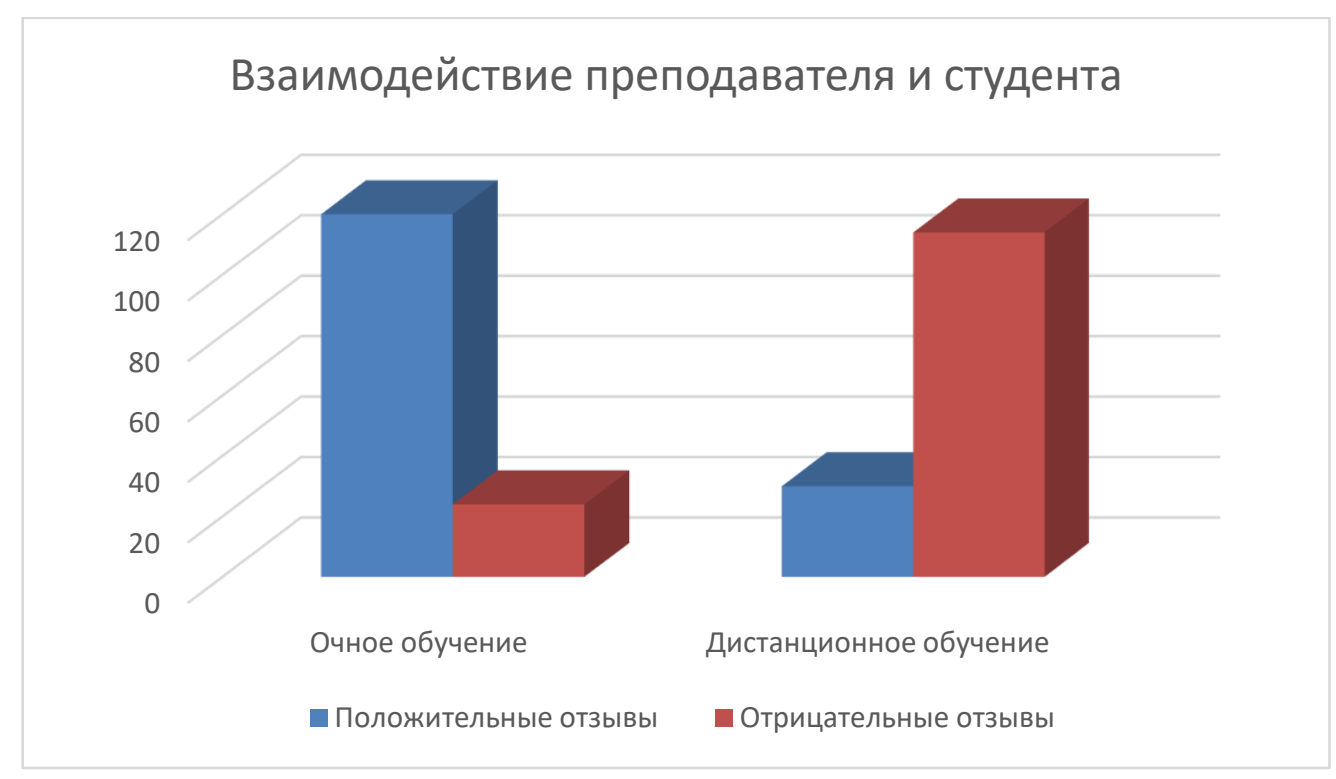

Диаграмма 6. Сравнение взаимодействия между преподавателями и студентами при очном и дистанционном формате обучения

Из диаграммы 6 видно, что намного больше студентам нравится взаимодействовать с преподавателем на очном обучении. Около 79,1\% студентов испытывают трудности при взаимодействии с преподавателем на дистанционном обучении, стоит отметить, что в Дубайской школе бизнеса эта цифра не превышает 33,1\% [4].

Можно сделать выводы, что по сравнению с Дубайской школой бизнеса у студентов Крас ГМУ, более грамотно составлено расписание занятий, потому что у меньшего количества наших студентов возникают проблемы с распределением времени. Однако, нужно уделить больше внимания на коммуникацию со студентами при дистанционном формате обучения. [5]

Заключение. Анализ теоретической информации, разных способов интерактивного обучения и проведенный опрос позволили нам сформулировать и систематизировать наиболее эффективные для дистанционного обучения форматы.

Большое внимание при дистанционном формате обучения стоит уделить получению практических навыков студента, так как, по результатам опроса огромное количество студентов не получают практические умения на 
дистанционном формате обучении. Следующим немаловажным аспектом стало снижение усвоения информации, по нашему мнению, эта проблема решаема следующим образом: пополнением банка видео-лекций и видеоматериалов, созданию собственных, более развернутых методических материалов кафедрами, в которых все будет описано современным языком в различных форматах. Также преподавателям следовало бы создать больше интерактивности на занятиях в дистанционном формате, это помогло бы создать большую вовлеченность студента в процесс, и как следствие улучшить восприятие информации и повысить уровень взаимодействие со студентом. [6, 7].

Для полной оценки взаимодействия студент-преподаватель, следует провести опрос у профессорского-преподавательского состава, исследование продолжается.

\section{Список литературы}

1. Приказ Минобразования РФ от 30.05.1997 г. №1050 «О проведении эксперимента Леванов В.М. Формирование электронной информационнообразовательной среды непрерывного медицинского образования / В.M. Леванов, И.А. Камаев, С.Н. Цыбусов, А.Ю. Никонов. Н.Новгород, 2016. 312 с.

2. Приказ Министерства просвещения РФ от 17 марта 2020 г. № 103 “Об утверждении временного порядка сопровождения реализации образовательных программ начального общего, основного общего, среднего общего образования, образовательных программ среднего профессионального образования и дополнительных общеобразовательных программ с применением электронного обучения и дистанционных образовательных технологий” [Электронный pecypc]. URL: http://www.consultant.ru/document/cons_doc_LAW_348150/2ff7a8c72de3994f304 96a0ccbb1ddafdaddf518/

3. Постановление Правительства РФ от 18.06.2020 N 876 "О внесении изменений во Временные правила оформления листков нетрудоспособности, назначения и выплаты пособий по временной нетрудоспособности в случае карантина застрахованным лицам в возрасте 65 лет и старше" [Электронный pecypc]. URL: http://www.consultant.ru/document/cons_doc_LAW_355376/

4. Nasser A. Saif Almuraqab. (2020). SHALL UNIVERSITIES AT THE UAE CONTINUE DISTANCE LEARNING AFTER THE COVID-19 PANDEMIC? 
REVEALING STUDENTS' PERSPECTIVE. [Электронный ресурс]. URL: https://www.ncbi.nlm.nih.gov/pmc/articles/PMC7366799/

5. Агранович Н. В., Ходжаян А. Б., Сохач А. Я., Щетинин Е. В. Дистанционное обучение как современная форма обучения медицинских кадров // Медицинский вестник Северного Кавказа. 2012. №2.

6. Алексеева С.Н., Антипина У.Д., Дмитриева О.Н. Проблемы перехода на дистанционное обучение при изучении дисциплин «латинский язык» и «патофизиология» // МНКО. 2020. №4 (83).

7. Лазаренко В. А., Калуцкий П. В., Дрёмова Н. Б., Овод А. И. Адаптация высшего медицинского образования к условиям цифровизации здравоохранения // Высшее образование в России. 2020. №1.

\section{Сведения об авторах}

Бабаджанян Акоп Манасович, Клинический ординатор кафедры общей хирургии, Специальность пластическая хирургия. Научный руководитель. Красноярский государственный медицинский университет имени профессора В.Ф. Войно-Ясенецкого;

Гросс Дарья Юрьевна, студентка 1 курса, 107 группы, специальности лечебное дело, Красноярский государственный медицинский университет имени профессора В.Ф. Войно-Ясенецкого;

Кашинцев Вадим Алексеевич, студент 1 курса, 107 группы, специальности лечебное дело, Красноярский государственный медицинский университет имени профессора В.Ф. Войно-Ясенецкого; 